\title{
Etnografías desérticas. Reflexiones desde una antropología del nomadismo $^{1}$
}

\author{
Leticia Katzer ${ }^{2}$
}

\author{
Fecha de recepción: 23 de julio de 2018
}

Fecha de aprobación: 24 de octubre de 2018

\begin{abstract}
Resumen
El presente artículo contiene una serie de reflexiones, elaboradas sobre la base de nuestra propia investigación etnográfica, que intentan contribuir a desnaturalizar y visibilizar la complejidad de los contextos de interacción, considerando que abarcan distintas dimensiones y aspectos -tales como posición de los interlocutores en la estructura social, expectativas individuales, experiencias y relaciones previas de los sujetos, y recursos materiales y simbólicos en intermediación-, enfatizando así el carácter situacional y dinámico de esas relaciones de interlocución.

A la luz de los actuales debates de la crítica cultural, el pensamiento nómade y la crítica espectrológica derridiana, y en un intento por contribuir a los estudios de la Etnografía Colaborativa, el objetivo de este artículo es exponer lo que entendemos como performances de campo, situando como objeto de análisis la experiencia etnográfica en sí misma.
\end{abstract}

Palabras clave: espectrología, etnografía colaborativa, indígenas, nomadismo.

\section{Desert ethnographies. Reflections from an anthropology of nomadism}

\begin{abstract}
This paper contains a series of reflections developed on the basis of the author's own ethnographic research, carried out since 2004 with indigenous Huarpe people in the province of Mendoza, Argentina. These reflections try to contribute to denature the complexity of interaction contexts and make them
\end{abstract}

\footnotetext{
Este artículo presenta resultados de la investigación etnográfica llevada a cabo y financiada por el proyecto PICT de AGENPCYT “Etnopolítica y gubernamentalidad en contexto etnográfico. Tensiones epistémicas y jurídico-políticas entre 'comunalización' y rutinas de vida-en-común nomádicas de adscriptos étnicos Huarpes".

2 Doctora en Ciencias Naturales, área Antropología y licenciada en Antropología por la Facultad de Ciencias Naturales y Museo de la Universidad Nacional de La Plata, Argentina. Investigadora del Consejo Nacional de Investigaciones Científicas y Técnicas, Mendoza, Argentina. Contacto: 1katzer@mendoza-conicet.gob.ar
} 
visible, considering that such contexts embrace different dimensions and aspects -such as the speakers' position in the social structure, individual expectations, experiences and previous relationships of subjects, as well as material and symbolic intermediation resources. Emphasis is therefore placed on the situational and dynamic character of those interlocution relationships.

In the light of current debates from cultural review, the nomad thinking and the Derridean spectrological critics, and in an effort to contribute to the Collaborative Ethnography studies, this paper is aimed at showing what we understand as field performances, considering the ethnographic experience itself as the object of analysis.

Keywords: Collaborative Ethnography - Indigenous people - Nomadism Spectrology

\title{
Etnografias desérticas. Reflexões desde uma antropologia do nomadismo
}

\begin{abstract}
Resumo
O presente artigo contém uma série de reflexões elaboradas sobre a base de nossa própria pesquisa etnográfica. Estas reflexões tentam contribuir a desnaturalizar e visibilizar a complexidade dos contextos de interação, considerando que abrangem diferentes dimensões e aspectos -tais como posição dos interlocutores na estrutura social, expectativas individuais, experiências e relações prévias dos sujeitos, e recursos materiais e simbólicos em intermediação-, salientando assim o caráter situacional e dinâmico dessas relações de interlocução.

À luz dos atuais debates da crítica cultural, o pensamento nômada e a crítica espetrológica derridiana, e em uma tentativa por contribuir aos estudos da Etnografia Colaborativa, o objetivo deste artigo é expor o que entendemos como performances de campo situando como objeto de análise a experiência etnográfica em si mesma.
\end{abstract}

Palavras-chave: Espetrologia- Etnografia colaborativa- IndígenasNomadismo.

\section{Introducción}

En cualquier ámbito en el que llevemos adelante nuestra tarea etnográfica, muy difícilmente nos encontraremos con un espacio individualizado, uniforme y homogéneo. Este ha sido nuestro caso respecto de la población indígena Huarpe de la provincia de Mendoza, República Argentina. Si reconocemos que la etnografía es la interpretación de un marco de referencia compartido (Guber, 2001), éste se nos hace presente como una matriz múltiple de valores, significantes, interpretaciones, percepciones, así como trayectorias disímiles entre sí. Por otro lado, los marcos de refe- 
rencia se ven no solo diversificados sino también desigualmente legitimados. Entonces, la cuestión es evaluar qué objetivamos como "común", qué marcos/universos estamos seleccionando como objeto de registro, cuáles son las trayectorias que se diferencian al interior de los mismos y con qué legitimidad. Así, más que interpretar y reconstruir un marco de referencia compartido, entendido como una unidad semántica, se trata de diseminar los itinerarios que lo alterizan y diversifican. En este sentido más que en un grupo o colectividad objeto de registro, hemos pensado en una red de trayectorias multisituadas y estructuradas en circuitos colaborativos (Katzer, 2011).

Este trabajo pretende ser una contribución a la reflexión metodológica etnográfica, sobre la base de nuestra propia experiencia de campo, fundada en terreno durante más de trece años (2004-2018) con adscriptos Huarpes de la zona del "desierto" del nordeste y conurbano de la provincia de Mendoza, República Argentina ${ }^{3}$. Ponemos en primera línea de reflexión la experiencia de campo directa, con todos sus matices: la observación de las rutinas, el diálogo, el compartir actividades significativas para el lugar, los afectos, las fracturas, en fin, todo lo que se pone juego en el hacer etnografía de manera intensa y prolongada. La revisión crítica de nuestra propia experiencia nos permite observar y señalar la presencia de formas de relación, concepción y va-

\footnotetext{
"Desierto" o "secano" constituye la "zona no irrigada" de la provincia, aquella que carece de sistema de riego artificial, que no se destina a explotaciones agrarias intensivas y que se consigna preferentemente para la actividad pecuaria extensiva; actividad que se inicia a partir de la reducción de los indígenas. La población general se halla heterogéneamente dispersa, es decir, en los puestos, que constituyen unidades productivas y residenciales de familias nucleares, con una distancia promedio entre de $10 \mathrm{Km}$. aproximadamente entre sí, unas 3 horas a pie, si las condiciones climáticas y los accidentes del terreno lo permiten (guadales, médanos, montes, etc.). Existen, además, pequeños poblados/parajes -caseríos de no más de 30 viviendas-, entre los que se destacan Lagunas del Rosario, Asunción, San José y San Miguel (antiguas reducciones). Sumado a esta área, estamos con la comunidad Huarpe de Uspallata y las organizaciones urbanas. Cabe señalar que registramos dos grandes dinámicas: por un lado, las "comunidades indígenas" y organizaciones, formadas jurídicamente, $y$, por otro, redes de familias relativamente aisladas campo dentro, ajenas o no involucradas de manera activa con la "organización formal".
} 
loración del otro en distintos contextos de interacción como de coyunturas del propio proceso etnográfico. Es decir, la reflexión sobre la experiencia de campo directa se nos hace patente en dos dimensiones indisociables: la procesual y la experiencial.

Veremos que hay aspectos del proceso etnográfico que se nos fueron apareciendo como entidades carentes de representación y de objeto, volviéndosenos vehiculizables en el registro y en el relato solo como rastros, huellas y restos. Experiencias en las que nos hacen resonancias las filosofías nómades y desérticas de la deconstrucción y la espectrología, con las cuales simultáneamente hemos estado en conversación. Es por ello que recurrimos a los aportes de los filósofos Jacques Derrida y Massimo Cacciari para elaborar un horizonte de reflexión que posibilite revisar el campo de la etnografía desde nuevos ángulos y complejidades. Entendemos que estas semánticas son verdaderos nutrientes de pistas de decolonización del saber etnográfico, así como de potenciación de una actitud científica con la cual nos identificamos: la actitud científica itinerante, también llamada por Deleuze y Guattari (1980) la "ciencia nómada".

Entendemos que no cualquier forma de etnografía puede encarar estos registros, sino una de las huellas y de los rastros, una etnografía que no busca representaciones cerradas, una etnografía de la sensibilidad que pueda entrar en esos espacios sutiles que estructuran la vida en los "desiertos" y en las lógicas "nómades". La hemos llamado "etnografía filolítica", puesto que descompone, desliga, disgrega, disuelve, disemina desde una matriz que no solo busca "reconstruir" itinerarios de subjetivación/personalización étnica en el ámbito de las representaciones, sino centralmen-

\footnotetext{
"Filolítica" es una palabra que propone Derrida para analizar procesos desde una perspectiva diferente a la de la filiación como búsqueda del origen, la cual el autor identifica con ciertos planteos genealógicos. La filolítica es un movimiento de disolución, es la experiencia de la disociación hiperanalítica de lo simple y lo originario que empuja a la desedimentación de las subjetivaciones, en toda la gama de sus idealizaciones, presupuestos, instituciones, técnicas, dispositivos (Derrida, 1996).
} 
te deconstituir conceptos, presupuestos, instituciones, técnicas, e identificar tanto vivencias como marcas y huellas (Katzer, 2015).

Hay muchas maneras de hacer y orientar la etnografía. Y estamos convencidos de que la orientación la da no solo el posicionamiento teórico e ideológico del etnógrafo/a sino fundamentalmente su sensibilidad, su estilo de relación, su manera de conectarse sensiblemente con el entorno de estudio. Es decir, lo que compete al orden de la experiencia. Este es el foco de nuestro análisis.

\section{Enfoques etnográficos}

La etnografía nace como contradiscurso bioantropológico respecto del objeto y la naturaleza del objeto. Mientras que la antropología evolucionista había universalizado la naturaleza de la especie humana, la etnografía buscó definir su naturaleza desde la particularidad y por oposición a su dimensión biológicanatural-viviente-animal. Pese a este aparente giro teórico/metodológico revolucionario, en su momento fundante, la etnografía expresa primeras epistemologías y metodologías coloniales. Esta matriz colonial se expresa tanto en el modo de relación con los sujetos etnografiados como en el tipo y forma de instrumentalización del saber producido, operativizado por la gestión de la población en las administraciones coloniales (Asad, 1973; Wolf, 1982; Stocking, 1991). En nuestro contexto de estudio, son muchos los signos textuales que expresan la matriz colonial, la linealidad y la jerarquía con que se ha concebido y llevado adelante la relación etnográfica, relevada por nosotros en otros trabajos anteriores (Katzer, 2016). Si bien las etnografías clásicas se dedicaron a refutar la tesis racista de la producción antropológica del siglo XIX, y descentrar la noción de "raza" como categoría de análisis, los modos de clasificación y relación etnográfica que expresan no parecen ser tan discontinuos.

En la actualidad se le atribuye el éxito a la trascendencia de los límites de la disciplina de la etnografía. Cabe recordar que ésta nace en diálogo transdisciplinario, fundamentalmente con 
la filosofía y el psicoanálisis (Katzer, 2016). En su momento fundante, la asociación de la etnografía con la filosofía y con el psicoanálisis es explícita. Ruth Benedict, en Patterns of culture (1934), traduce las formas de valores de existencia expresados en la tragedia griega estudiados por Nietzsche (apolíneos y dionisíacos) al análisis de los pueblos indígenas por ella etnografiados (Benedict, 1934, pp. 72-73). La idea de "plasticidad", que hallamos tanto en la obra de Benedict como en Mead, es una noción nietzscheana. Para Evans-Pritchard (1962), la antropología es un tipo de historiografía y, en último término, de filosofía, en el sentido de que no estudia sistemas naturales sino sistemas éticos, diseños y patrones. Bronislaw Malinowski en Argonauts of the Western Pacific (1922), en Myth in primitive psychology (1926) y en The father in primitive psychology (1927), utiliza un lenguaje psicoanalítico y una explícita adherencia a su vocabulario. El mismo Sigmund Freud, en Totem y tabú (1913), expone reflexiones sobre la cultura "primitiva" a partir de las lecturas que hizo de la obra de J. G. Frazer (Freud, 2012 [1913-14], p. 105).

Los relatos y las formas de relación construidos en el seno de las etnografías han sido y continúan siendo de lo más disímiles, variando entre "etnógrafos asaltantes", "etnógrafos indiferentes" y "etnógrafos comprometidos" (Restrepo, 2016). Estas formas pueden responder a un modelo de relación arbitrario y violento (propio de lógicas coloniales de producción de conocimiento), a un modelo de indiferencia o a un modelo colaborativo, comprometido y sensible con las inquietudes, iniciativas, con la vida misma de los etnografiados/as. En cualquiera de los casos, la agentividad política del etnógrafo/a es innegable, porque realmente de lo que se trata es de la vida, del registro de modos de vida, de modos de vida-en-común, es decir, de la construcción de lo comunitario que hace a nuestra condición de vivientes diversos entre sí y que nos politiza en consecuencia.

Cuando reflexionamos sobre la colonialidad del saber y sus posibilidades de decolonización (Lander, 2000; Quijano, 2002) no puede omitirse la reflexión sobre cómo construimos las relaciones 
etnográficas. La espacialidad de la decolonialidad refiere tanto a la estructura epistémica, a una metafísica, a los saberes/positividades que desde esa estructura son delimitadas, como a las formas de relación con el sujeto de estudio. Decolonizar saberes implica decolonizar no solo los sistemas epistémicos, los sistemas metafísicos, las positividades, sino fundamentalmente las formas de relación con los sujetos de estudio; de otro modo, deviene como mera enunciación general, esquemática, globalizante.

La etnografía ha sido pensada desde tres aspectos: texto, enfoque o perspectiva, y método o herramienta (Guber, 2001). Nuestra reflexión va orientada a pensar la etnografía en otra dirección, ni como método ni como enfoque. Más que una "herramienta", cada etnografía es un específico modo de ser, hacer, pensar y estar con el otro. Más que un "medio" es un "modo". Hay modos diferentes de hacer etnografía, por lo que cada etnografía y trabajo etnográfico tiene su perspectiva y estilo específicos.

La redefinición de las etnografías como una forma de escritura, como narrativas, emerge con la teoría crítica que vino a denominarse "Writing culture" (Clifford y Marcus, 1986), continuada y reformulada a posteriori en las producciones de Thomas (1991), Fabian (1991), Rapport y Overing (2000) y Trouillot (1995, 2003). Esta crítica, centrada en la dimensión textual-representacional del registro etnográfico, se vuelca a la descripción y análisis de la etnografía como un género distintivo de escritura, recuperando la problematización del colonialismo, de las formas de dominación, desigualdad y poder en las categorizaciones de la alteridad dentro de las situaciones etnográficas, que había inaugurado la crítica anticolonial de los años 60/70 (Balandier, 1951; Gluckman, 1958; Worsley, 1967; Asad, 1973). Estas perspectivas críticas contemporáneas se han centrado sobre las formas narrativas de construcción del otro, en el aspecto textual de la producción de la alteridad en el proceso etnográfico.

En esta perspectiva, el trabajo de campo no es considerado como experiencia iniciática que legitima la formación antropo- 
lógica, sino como una práctica constante (Bartolomé, 2002); tampoco un accidente episódico y fortuito que instaura una mera relación cognoscitiva, sino que los valores y saberes indígenas constituyen parte imprescindible de la construcción sociológica del sujeto observante (Pacheco de Oliveira, 2006). Así, se considera el espacio etnográfico como un espacio de producción de conocimiento conjunto (Tamagno, 2001), siendo definido como una "co-teorización" académica-indígena (Rappaport y Ramos Pacho 2005) y como un proceso colaborativo (Lassiter, 2005), y las relaciones entre los interlocutores como relaciones simultáneamente balanceadas y mutables, con alteraciones y ajustes.

En diálogo con la línea de pensamiento que entiende a la etnografía como un estilo de producción de conocimiento social (Lassiter, 2005; Marcus, 2008), puntualizamos en el aspecto sensitivo, vivencial y experiencial sobre cómo se construye la relación con el otro, cómo se siente esa relación y lo que de ella resulta en tanto trabajo colectivo. Nos focalizamos en el análisis de las micropolíticas de la sensibilidad, traducido en nuestro trabajo en una "espectrografía", es decir, en la cartografía de las huellas y de los registros espectrales (Katzer, 2015). En ello retomamos el valor fundante de la conexión de la etnografía con la filosofía. La etnografía constituye en sí misma un horizonte de reflexión filosófica, puesto que los registros y experiencias que allí germinan constituyen materiales de reflexión sobre la vida humana, sobre la vida en común (Katzer, 2016). Desde ese lugar epistémico, buscamos contribuir a desnaturalizar y visibilizar la complejidad de los contextos de interacción en situaciones etnográficas, siguiendo pistas de deconstrucción de las epistemologías y metodologías coloniales de la etnografía.

\section{La etnografía como proceso}

Cuando historizamos nuestra propia experiencia de investigación identificamos al menos tres momentos diferentes, en los cuales a su vez varían los modos de las relaciones, las técnicas 
y las dinámicas. La etapa inicial del proceso etnográfico estuvo caracterizada por el diálogo con actores más públicos y abiertos a gente del "afuera", tales como líderes, actores con función pública, todos ellos con recursos simbólicos y materiales familiares a la cultura occidental/moderna. Y todos ellos partícipes, miembros de las organizaciones indígenas. En tanto primer contacto, los cuerpos y rostros expresan distanciamiento y susceptibilidad, que no solo reside en el mutuo desconocimiento sino también, y creemos fundamentalmente, en ser ante su mirada representantes de una institución o, mejor dicho, de una relación social -academia/indígena- construida como relación de poder. Al contacto entre el etnógrafo y los actores indígenas, preexiste, coexiste y prevalece un contexto histórico colonial global marcado por la dominación del blanco sobre los no blancos. Este distanciamiento limita al mínimo el uso de dispositivos de registro, como el cuaderno de notas, el grabador y/o la cámara fotográfica ${ }^{5}$. Recordamos esta etapa como un momento muy duro, difícil, de grandes esfuerzos por derribar barreras de comunicación.

Despejados los preconceptos, qué investigar y cómo se convierte en algo a acordar con el otro. La naturalizada "entrada al campo" de "nativos" dispuestos a colaborar como "informantes" deja de ser un espacio prefijado, estable y por sí mismo legítimo, para pasar a entenderse como sucesivas "reuniones", en las que la discusión acerca de los objetivos, y posibles resultados de la investigación es lo que otorga la efectiva legitimidad al inicio del trabajo etnográfico. Aquí se inicia un segundo momento, en el que el logro de cierta confianza otorga la legitimidad para hacer uso de cualquier tipo de dispositivo de registro (cuaderno, grabador, cámara fotográfica, etc.).

Es el momento en el que nos involucramos más con el lugar y la gente, expandiendo los lazos, y cuando, en consecuencia, co-

En este contexto, el recurso de registro era retener la información y luego plasmarla en el cuaderno de notas de manera privada, al momento de ir a dormir. 
menzamos a conocer personajes y puntos de vista distantes entre sí y universos de vida completamente distintos. Y aquí comienza también un momento caracterizado por la búsqueda de actores, prácticas e identificaciones por fuera de los circuitos sociales que marcaban las "comunidades" y las "organizaciones"'. También de identificación de trayectorias y circuitos colaborativos, marcados por las relaciones con agencias de lo más variadas: agencia gubernamental, organizaciones indígenas y campesinas, agencia religiosa con injerencia local7.

Y un tercer momento está dado por la consolidación de las relaciones en una red y circuito de mutua confianza y colaboración. La construcción de la relación con los interlocutores en general y con los "consultores claves" en particular es, respecto a etnógrafos/as y etnografiados/as, mutuamente selectiva, momento en el que nuestro trabajo comienza una articulación real y concreta con diferentes instituciones vinculadas a la gestión: empresas, ONGs y áreas gubernamentales, con las cuales co-

\footnotetext{
Cabe señalar aquí que los Huarpes se nuclearon jurídicamente en doce "comunidades indígenas" entre 1998 y 1999. En 2013 se agregó una más, con pertenencia jurisdiccional en San Luis.

7 En nuestro contexto etnográfico registramos al menos cuatro circuitos colaborativos, a los cuales nuestra práctica se articula: el que ha resultado de la articulación de un conjunto de líderes con ENDEPA (Equipo Nacional de Pastoral Aborigen), el que ha que nucleado a líderes clusters, funcionarios del gobierno y empresas; el que resulta de la articulación de aquellos líderes con funcionarios del gobierno provincial y municipal, y el de las organizaciones indígenas de alcance provincial y nacional, como son la ONPIA (Organización de Naciones y Pueblos Indígenas en Argentina) y las organizaciones "Martina Chapanay", "Identidad Territorial Malalweche" y "Pewel Katuwe". Podríamos agregar un quinto circuito, que articula la Unión de Trabajadores sin Tierra (UST), quienes trabajan conjuntamente con el INTI y la Secretaría de Agricultura Familiar.

Las áreas del gobierno implicadas con mayor presencia en las trayectorias étnicas del contexto etnográfico lavallino, son centralmente la Municipalidad y el IDR (Instituto de Desarrollo Rural, organismo público/privado de provincia), sumado a INTA, INTI, Dirección de Recursos Naturales Renovables, Secretaría de Agricultura Familiar, programa provincial de Chagas, con más o menos alcance según los casos. Como parte del escenario etnopolítico se anexan la Mesa caprina (Dirección de Ganadería de la Provincia); la Dirección General de Escuelas (DGE), con el programa de becas y organización de foros; la Mesa del agua; la Red Argentina de Turismo Rural Comunitario (RATURC), y el Arzobispado, con diferentes formas de intervención y articulación con las comunidades indígenas.
} 
menzamos a trabajar de manera conjunta, acercando la etnografía con la gestión. El propio proceso etnográfico o, mejor dicho, la dinámica que fueron adquiriendo las relaciones etnográficas, fue orientando las acciones académicas y relaciones institucionales hacia la gestión de proyectos comunitarios de desarrollo, la gestión patrimonial y la gestión cultural/turística en área claves como el hábitat, la energía y la gestión patrimonial de restos arqueológicos. Al contactarnos con mayor profundidad con las iniciativas y demandas nativas, y al fortalecer las relaciones interinstitucionales gubernamentales en distintas escalas de estatalidad, comenzamos a intentar vehiculizar los resultados de nuestra investigación en proyectos concretos, en acciones concretas para la gente. Aquí es donde se revela el trabajo colectivo en un doble sentido: en tanto resultante de un largo proceso de construcción de confianza, afecto, y en tanto deseo de "hacer" algo con el otro (y no solo "conocer al otro"). Nuestra etnografía colaborativa se conecta con la gestión en tres propuestas centrales que estamos trabajando, a saber: 1) poner en valor la quincha/barro y el junquillo como recurso cultural y recurso sustentable para la edificación (trabajado con la Dirección de Recursos Naturales Renovables del gobierno de la provincia de Mendoza. Realizamos dos talleres, uno en construcción en tierra cruda, mediante el cual realizamos la restauración colectiva de partes de la capilla de San José; y otro de trabajo artesanal en junquillo, dictado por una nativa); 2) trabajar de manera articulada con la ONG Electriciens Sans Frontières y la Municipalidad de Lavalle para proveer de electricidad, mediante energía solar, a familias que carecen de este servicio, y 3) trabajar junto con las comunidades la forma de gestión de los restos arqueológicos (óseos, cerámicos y de vivienda) desparramados en el extenso territorio del "secano", sede de las "comunidades indígenas". Así, en distintos eventos que involucran al secano, compartimos almuerzos protocolares y actividades, fundamentalmente en ocasión de las fiestas religiosas, a las que asisten tanto las autoridades religiosas como las municipales. 


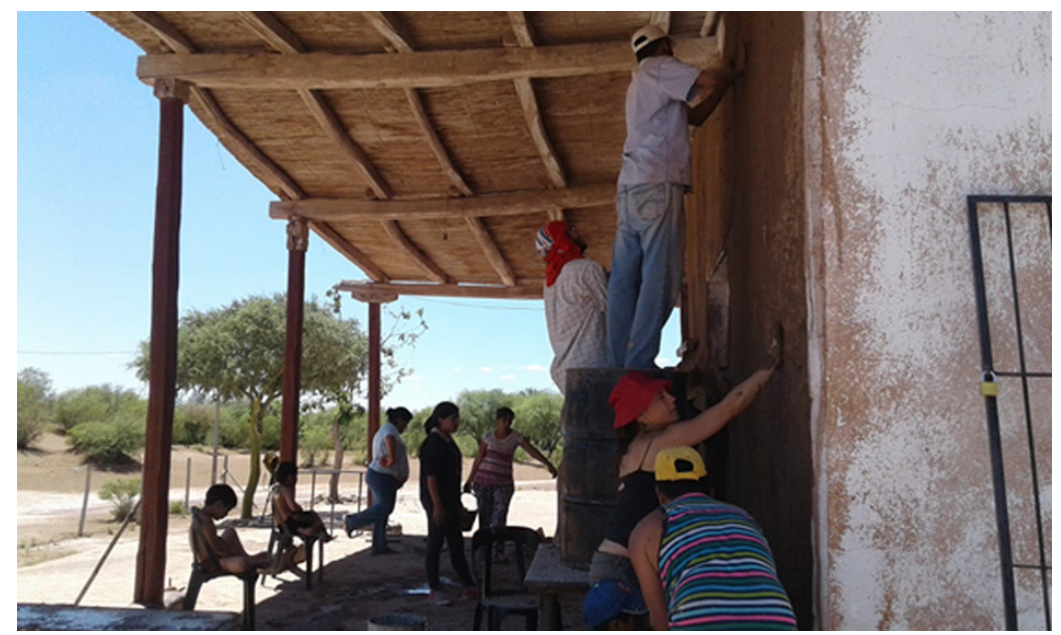

Fig. 1. La autora, junto con nativos, participando de la restauración comunitaria de la capilla (marzo de 2017). Se armó un piletón de barro que fue usado por los niños para juegos mientras revolvían la mezcla de barro. Al finalizar la jornada de trabajo compartimos una cena. Esta actividad tuvo un alto impacto en medios periodísticos locales.

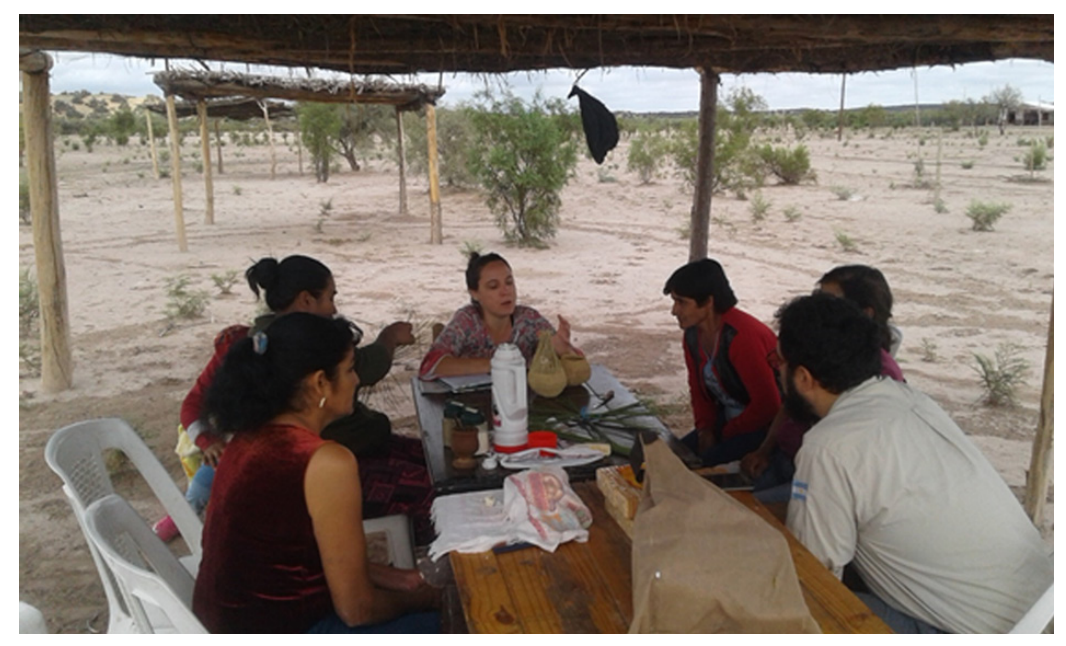

Fig. 2. Reunión de organización del taller de trabajo artesanal en junquillo, junto con las mujeres nativas de El Cavadito (mayo de 2018). Foto de Celeste Villegas.

Con todo, en el proceso etnográfico se van ampliando, bifurcando y consolidando redes de relaciones que delimitan dis- 
tintos espacios etnográficos, expresión de distintos itinerarios étnicos: unos más visibles, previsibles; otros más invisibles, "espectrales". Por ello, si etnografía es interpretación desde la perspectiva de los propios "actores" (Guber, 1991[2004]) y descripción de las rutinas (Marcus y Fisher, 1986), debemos estar muy atentos y mostrar la suficiente sensibilidad como para poder percibir la diversidad con que se expresa el universo etnográfico.

Puesto que la etnografía no es una mera relación técnica y cognitiva sino un vehículo imaginativo y personal (Clifford y Marcus, 1986), la calidad y autenticidad del trabajo etnográfico y su grado de logo-etnocentrismo dependerá del modo en que se articulen sus posibilidades creativas. Aquí cobra fundamental preponderancia, a nuestro entender, la transferencia dentro del espacio etnográfico. Para que la gente diga lo que piensa y hace, debe estar el deseo y la confianza de hacerlo. La gente elige qué decir, cuándo y de qué modo. Cuando se inicia una trayectoria compartida, surgen las ganas de contar, los relatos surgen espontáneamente, como así también las rutinas más sutiles y más significativas, o salen a la vista o pueden ser vistas, porque ha cambiado la matriz de visión, percepción y de interacción. En ese proceso aparece el deseo de decir, el deseo de compartir, y la palabra dicha toma sentido puesto que cada interlocutor se reconoce como tal. Si no hay amistad -más precisamente, una específica política de amistad-, no hay etnografía sensata. La investigación etnográfica, que se inicia desde un inevitable lugar de mutua extrañeza, prejuicio, timidez, desconfianza y temor con los nativos, se convierte en el devenir etnográfico en un espacio deseado al que se extraña, quiere y espera, como así también en un espacio dirigido casi absolutamente por los otros: los tiempos, los relatos, los problemas, las expectativas y las exigencias. Y también en un espacio placentero, en el sentido del disfrute de lo compartido, de que nos brinda orgullo y certeza a la vez. Ese es el espacio etnográfico, ese en el que la forma del "nosotros" excluyente se diluye, para dar lugar a la 
exposición radical de los otros, entre los cuales el etnógrafo es otro más.

Si la especificidad de la etnografía es la de ser una concepción y práctica de conocimiento que busca comprender los fenómenos sociales desde la perspectiva de sus miembros (Guber 1991[2004]; 2001) ésta solo es posible cuando se establece auténticamente una relación entre el etnógrafo y esos otros. Los nativos seleccionan qué decir y qué no, qué distorsionar y que no, según sea a quién, por qué y para qué. Poniéndonos en contacto con todo este proceso, podemos aseverar que lo que la gente muestra, expone y cuenta tiene más relación con la relación empática que se construye -y con lo que se puede conocer también de las rutinas compartidas producto de esa relación-, que con una mera neutral e instrumental relación cognitiva. Cuando se desconoce al otro y, más aún, cuando el otro que indaga encarna la historicidad de una relación colonial (como es la relación de la academia y el Estado respecto de las etnicidades), hay desconfianza y no hay motivación para contar nada, o la hay solo para mostrar y contar muy poco. ¿Por qué, para qué contar? Estas preguntas son las que marcaron los dos primeros años de trabajo de campo.

Con todo, en los contextos de producción de conocimiento etnográfico se ponen en juego intereses y estrategias diversas, a veces en contradicción, pero sobre un marco en el que las acciones, creencias y expectativas se articulan, determinando o modificando el comportamiento y la participación. En la situación etnográfica, los interlocutores traen consigo expectativas, recursos materiales y simbólicos, experiencias y relaciones previas que, en conjunto y articuladas, condicionan y definen los patrones de interacción establecidos, imprimiendo en estos diferentes dinamismos. Los posicionamientos de los interlocutores no son ni definitivos ni estables, y su estado de situación, dinámico, define la continuidad, forma y calidad de la interacción, y, por ende, de la investigación y sus resultados. 


\section{La etnografía como experiencia}

Todo espacio etnográfico, en tanto espacio cultural, tiene un aspecto representacional y otro vivencial. Sin embargo, cierta herencia disciplinar se ha aferrado a los estudios que sobredimensionan el aspecto de la representación: mitos, leyendas, creencias, narrativas, textos, discursos. Esta disyuntiva es de larga data y toma visibilidad polémica en el Pensamiento Salvaje de Levis-Strauss (1962). La distinción deviene de la crítica que el autor realiza al "totemismo funcionalista". Frente al planteo de Malinowski -quien centró su atención en la "utilidad práctica" del totemismo-, Levi-Strauss propuso críticamente que las relaciones descritas por aquél eran relaciones "más concebidas que vividas", es decir, orientadas por fines teóricos y no pragmáticos (Levi-Strauss, 1980 [1962], p. 96). Cuando habla de la noción de "estructura" en etnología, en Antropología estructural, Levistrauss, alude a que, para la etnología, la sociedad se constituye de estructuras que corresponden a distintos órdenes, el orden de lo «vivido», «función de una realidad objetiva» (mirada de Malinowski) y el orden de lo «concebido») (mito, religión, ideologías políticas) ( Lévis-Strauss, 1962, pp. 235 y 236).

No en pocas conversaciones, en nuestro contexto etnográfico, referentes indígenas han cuestionado este estatus de centralidad de la idea de "creencia" para pensar la cultura indígena. Frases como "nosotros somos indios no solo por las creencias sino también por las vivencias (...) yo vivo como han vivido los indios" (HG, conversación año 2006), sumadas al esfuerzo por instalar la idea de una "cosmovencia" (a la par de "cosmovisión"), son sugerentes. Por eso, cuando hablamos de "registros etnográficos" lo hacemos con el sentido clásico de "registro" que le dio Horney, presentado en Linton (1945), y que incluye entonces no solo las operaciones de orden cognitivo, representacional, consciente, sino también el vivencial, perceptivo, háptico, sensitivo, tanto en el ámbito de indagación como en la misma dinámica de la relación etnográfica. Lo espectrográfico no satura en lo visible y en 
la palabra, sino que incluye otros registros como lo gestual. Ya Mauss (1926) advirtió de esta diferencia, proponiendo lo que él llamó el "método fonográfico", haciendo hincapié en la importancia de grabar no solo la voz, sino también de registrar golpes de pies y manos, y gestos; todo lo vinculado con la oralidad y los sonidos.

El trabajo etnográfico modela la sensibilidad. El ver, el sentir y el escuchar son subjetivos: se puede mirar y ver nada, o poco, o mucho; hay un proceso selectivo que define nuestra propia sensibilidad. Y esa selección está en el qué y en el modo y en la intensidad: qué vemos y cómo lo vemos y con qué intensidad. Lo que se ve, escucha y huele también implica un proceso y en un espacio "desértico" como el nuestro, requiere de aprendizajes. Nuestra sensibilidad no es natural, nuestros sentidos están moldeados y limitados en función de marcos culturales y de experiencias individuales y colectivas; están moldeados para registrar ciertas cosas y no otras. Cuando comenzamos a trabajar en el campo no vimos ni escuchamos ni olfateamos muchas cosas que hace un año sí. Por ejemplo, lo que significa el rastro, la huella en el lugar, que es fundamental en la estructuración de las rutinas del lugar. Aprender a ver las huellas y reconocerlas fue posible luego de un largo proceso de estar, compartir, sentir, escuchar y aprender a "campear"8 con los nativos. Nuestra sensibilidad se fue transformando y empezamos a sentir, ver, escuchar y oler cosas que antes no. Se activan los sentidos de otra manera. Eso se aprende también etnográficamente. Fue luego de un largo proceso que rastros que para nosotros eran absolutamente invisibles ante nuestros ojos, comenzaron luego a ocupar el lugar central de nuestra mirada y vista. Así, el campo fue transformando nuestra sensibilidad y nuestros sentidos. Esto es fundamental para la etnografía, para

\footnotetext{
Término utilizado por los nativos para hacer referencia fundamentalmente a la práctica de salir en búsqueda de los animales de pastoreo o de caza siguiendo su rastro, pero que denota cualquier forma de búsqueda en el campo (monte) a través de los rastros y huellas; también se le llama "salir a cortar el rastro".
} 
una etnografía sensata. No se trata solo de relevar los relatos, hacer entrevistas, observaciones, sino de entender los sentidos y la intensidad con que aparecen, captar la intensidad de lo sensible; hay que aprender a sentir como siente la gente.

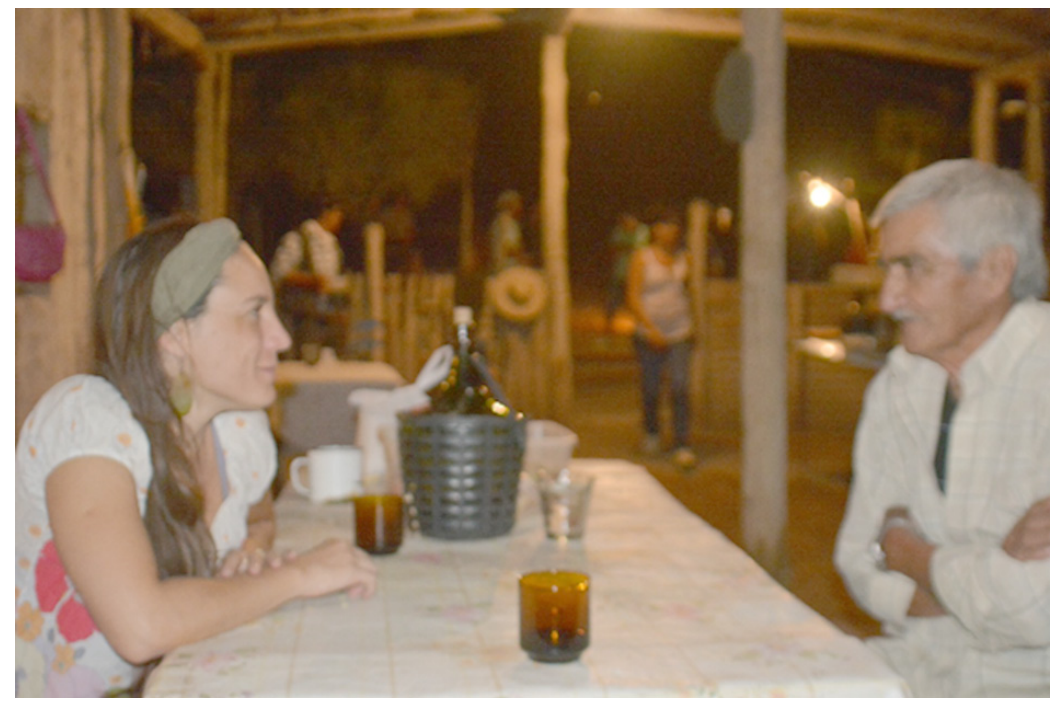

Fig. 3. Compartiendo cena en el ritual de San Vicente, un baile rogativo de lluvia al santo (febrero de 2015).

En tanto "experiencia", la etnografía implica pensarse como una forma específica de estar-en-común. Por ello, también, la etnografía es, en términos teóricos, indisociable de la cuestión de la comunidad. La experiencia refiere a cómo se vivencia el trabajo de campo de manera interna y colectiva, respecto de las modalidades e implicancias afectivas y políticas de las relaciones que se tejen, las identificaciones y oposiciones que se generan, las preocupaciones y expectativas comunes, las sensibilidades, las racionalidades, los estilos de vida, las búsquedas compartidas.

Lejos estamos de sostener que estas vicisitudes del trabajo etnográfico ponen en jaque el rigor y sistematicidad "científica", más bien pensamos lo contrario: es esta dinámica y estos componentes subjetivos y culturales lo que da rigor y sistematicidad al saber producido, lo que le brinda la calidad, rigurosidad, sereni- 
dad, autenticidad, así como también la sensatez al trabajo etnográfico. Entendemos que la cualidad y calidad de la experiencia etnográfica es la que posibilita que la pluralidad de rutinas se exprese.

Nuestra experiencia de campo es una experiencia de "desierto", en un sentido teórico y en un sentido empírico, sensible. La etnografía en el desierto es sobre todo una "espectrografía" (como la definió Derrida, 1993, una no-ontología): nos encontramos con taperas, vestigios de ranchos con objetos diversos, corrales, restos cerámicos, cadáveres y huellas de caminantes, difícilmente asimilables a una representación unívoca, a un cuerpo individualizado. Todos ellos con un fuerte sentido y valor de recuerdo y sentido de pertenencia para los nativos. El espacio etnográfico es un espacio trazado por múltiples huellas de "otros"; está asediado por múltiples fantasmas y espectros, y por ello mismo nos envía a la espacialidad del resto, del retazo, del rastro, que no es más ni menos que el espacio de lo común, en tanto alteridad presente-ausente. "Salir a cortar el rastro" / salir a campear" es, en el desierto lavallino, la forma de interacción social posible, en la cual las distancias entre puestos pueden llegar a muchos kilómetros y, por tanto, el contacto cara a cara es casi nulo; es una forma de socializar que implica salir a encontrarse con el otro a través de sus huellas; es entonces salir a encontrarse con el espectro del otro, con el espectro de la itinerancia del otro, la huella que deja el otro caminante en su andar, en su campeada (Katzer, 2015). El espacio etnográfico es desierto, en el sentido de lugar de los rastros. Aquí "desierto" queda despejado de su sentido más vulgar, prejuicioso, universalizado y naturalizado de espacio vacío, despojado de vida. Sentido que instalaron las "Campañas de la Nación" en el siglo XIX, y que continuaron reproduciendo los mismos antropólogos en su misma impugnación "no hay desierto". Nosotros mantenemos una concepción afirmativa. "Desierto" es el espacio semántico y sensible espectral ajeno al logocentrismo, la apropiación, el cálculo del interés y la estructuración analítica. "Desierto" es una manera de pensar, de estar y vivir. Está lleno de 
vida. Es el espacio del vivir itinerante, nómade. Por ello también proponemos una etnografía nómada, del espacio de lo nómade.

El universo desértico y nómade carece de representación unívoca. Es un pluriverso. El universo desértico y nómade es aorgánico. Esta condición de "resto", de "huella", de "espectro" lo hace difícilmente asimilable a una representación unívoca, una institución, una categoría, un término, un concepto o cuerpo individualizado. Si bien esto está muy reconocido en ciertas filosofías, el nomadismo y el pensamiento de la huella no tienen el mismo eco en la producción antropológica hegemónica americana. En buena parte del imaginario social y académico, la noción de "resto" presenta un estatus naturalizado de "cosa" que "queda", que permanece "presente" como pedazo de una unidad mayor que ya no tiene existencia, de una "cosa" mayor "muerta". Los pensadores del "resto" van en otro sentido, señalando su carácter de huella (y no de cosa), su carácter "circulante" y, fundamentalmente, su carácter "vital", de "vivo", de "perviviente", reconociéndole, por tanto, su potencial teórico-político.

\section{Etnografía "desértica" y pensamiento nómade: experiencia del "resto"}

En nuestro trabajo de campo hemos constatado que la identificación de los nativos con la referencia nómade se expresa en la palabra "campero". La figura de nómade coincide con la de "campero": el que campea, el que sale a campear. Campear en el desierto, salir a cortar el rastro, es serpentear entre las ruinas, entre los restos. Andar en el desierto pone ante los ojos, huellas, el rastro de las personas y de los animales, pisadas, olores; también restos de todo tipo: esqueletos, vestimentas, cerámicas, objetos personales, ranchos, ramadas a los cuales se les asigna espiritualidad, vitalidad, se los marca con crucecitas, respetando su lugar. Lo que se toma se vuelve a dejar en el mismo lugar. Cada evento histórico deja su rastro en el campo: los nombres de los bordos, los acontecimientos, lugares donde se produjeron acontecimien- 
tos. La aguada de la negra, la aguada de la india, donde se sentó la india a descansar. Muere una persona y queda todo allí intacto, se dejan sus pertenencia como si siguieran viviendo, presentesausentes, muertos y vivos a la vez. "Los indios gritan", nos cuenta TB, "cuando salgo a campear las cabras el indio les grita". Por eso uno recorre esos lugares y parece que los antiguos estuvieran ahí, presentes, porque quedan sus objetos y la gente los recuerda. La tapera de Sayanca, con restos de corral, restos de paredes y cerámicas desparramadas. Las casas "deshabitadas" de Javier Azaguate y Cipriano Fernandez, con todo el mobiliario. Están los vestigios de otro puesto en El Tupe, que también se llamaba "Los camperos", porque allí se reunían, entre otros muchos; el rancho de la abuela Matilde Reta, mamá de Javier Azaguate, con vestimenta, zapatillas, una silla y restos de una tinaja. También se encuentra el vestigio de rancho de Teodoro, con zapatillas y funda de guitarra; el rancho de Lorenzo Pérez, con azucarera, tenedores, una botella de aceite, vestimentas, una damajuana, un arco; todo como si estuvieran viviendo aún allí. A través de esos restos, su asedio espectral sigue presente-ausente.

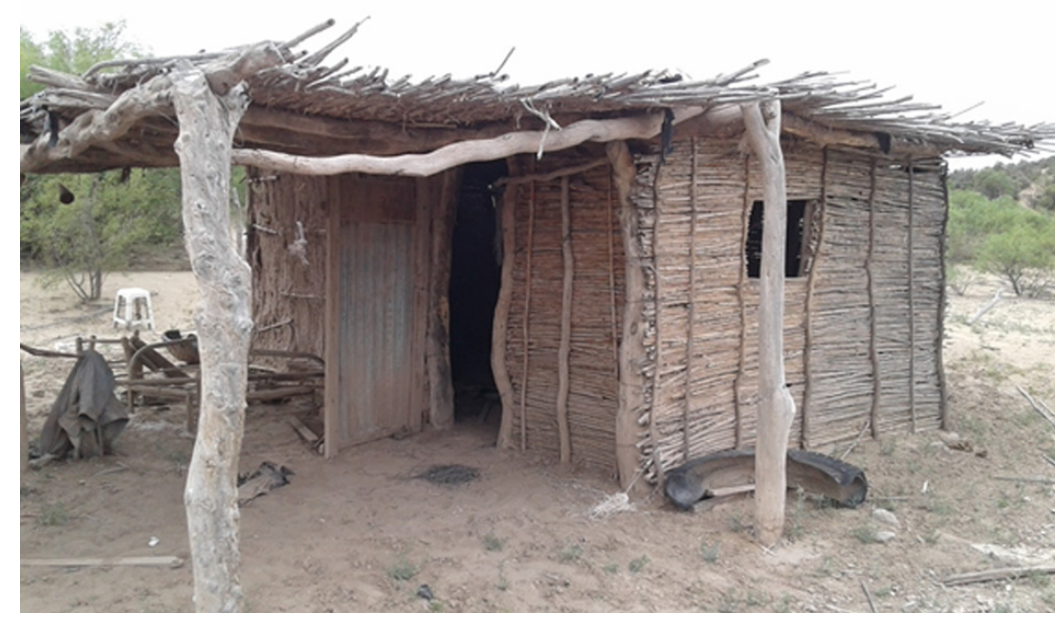

Fig. 4. Rancho deshabitado del difunto Lorenzo Pérez, con objetos personales diversos (octubre de 2016). Foto de la autora. 
En la zona de mayor cantidad de bosques de algarrobo y chañar también se encuentran vestigios de muchos "riales". El rial es una chocita hecha bajo un árbol, con palos de algarrobo y ramas de jarilla arriba. Es un campamento/refugio armado durante la recolección de algarrobo y leña. También hay vestigios de ramadas de "San Vicente". Así merodea el espectro del otro, el otro está presente/ausente. Por ello, las cartografías nativas son espectrografías en un doble sentido: porque se trata de registros de "restos" y porque se siguen las huellas para relevar los puestos?.

El término "espectropoética" es acuñado por Derrida, en su obra Espectres de Marx (1993), para dar cuenta de un léxico epistemológico que refiere a la presencia viva de la ausencia en el modo de marca o huella. No remite a la ausencia como modificación de la presencia, o como verdad velada a develarse, como sentido oculto a interpretarse o descifrarse, como contenido inconsciente-reprimido a ser descubierto, sino que remite a la posibilidad estructural de ser irreductiblemente y más allá de la presencia de los referentes, los contextos, los sujetos; más allá de la percepción presente.

Fig. 5. Médanos de Altos Limpios (octubre de 2016). Foto del equipo de producción del documental Nómadas. La búsqueda compartida (INCAA), de la cual la autora fue productora, guionista y protagonista.

Aquí "resto" toma un sentido muy diferente del que tradicionalmente le asignaron las etnografías clásicas. Consecuentes con la fenomenalización etnológica, los "clásicos" han entendido que "resto" era aquello que no podía ontologizarse, bajo el supuesto de

El "puesto" constituye una unidad residencial y productiva. Incluye la vivienda, la ramada y el corral de animales. 
que lo que no hace presencia como una totalidad viviente no existe en cuanto tal y/o se encuentra destinado a un proceso de extinción. Se lo define como un pedazo de una sustancia esencial que ya no tiene devenir y que se encuentra destinado a desaparecer. En tanto contingencia, se lo define no por su potencial creativo sino como un residuo susceptible de degeneración. La documentación de la heterogeneidad difusa se interpreta como "supervivencias", "objetos residuales preservados", siendo estos términos retóricamente usados como categorías para ontologizar, fijar, cosificar, petrificar $\mathrm{y}$ remitir a un pasado superado lo que se cree se ha perdido (Katzer, 2016). El resto-residuo-vestigio se define como aquello que no está habitado, y no habita de manera objetal y esencial como un todo orgánico, homeostático y presente, sino que asedia, y consecuentemente se halla destinado a la disolución.

Este concepto de "resto vestigial" tiene un sentido muy distinto al derridiano y al que nosotros identificamos en la experiencia etnográfica desértica. Los pensadores del "resto" van en otro sentido, señalando su carácter de huella (y no de cosa), su carácter "circulante" y, fundamentalmente, su carácter "vital", de "vivo", de "perviviente", reconociéndole, por tanto, un potencial teórico-político. En este esquema hay una concepción positiva del "resto", definiéndolo no como aquello destinado a desaparecer o morir, sino todo lo contrario. Aquí "huella" queda conectada al poder constitutivo, a la potenciación de la vida de lo viviente.

Para Derrida, "resto" es todo lo contrario a muerte y desaparición: lejos de vincularse a una "porción restante", a lo "que queda", resultado de un proceso selectivo, la pervivencia es una condición estructural de lo viviente, que conecta la vida y la muerte no como entidades puras y opuestas sino como un ensamblaje. Lo que vive siempre sobrevive, no el sentido de una pura vida, sino de una vida que lleva algo de muerte, y de una muerte que lleva vida al modo de huella.

Así como históricamente ha habido una conceptualización negativa de la palabra "resto", la ha habido también respecto de 
la palabra "desierto". El desierto siempre ha sido definido desde la carencia, con más fuerza aún en la llamada "Campaña del desierto". Y los antropólogos siguieron reproduciendo esa idea de desierto como "vacío de vida, de gente", impugnando el mismo concepto, porque por oponerse a esa idea civilizatoria y racista sentenciaron que no había que hablar de desierto, que habiendo gente y vida no había que hablar de desierto. Aquí sostenemos lo contrario, defendemos la idea de desierto pero no definido desde la carencia. Desierto se define como espacio deshabitado, lo cual no quiere decir vacío de gente y de vida, porque habitar significa colonizar y cultivar. Entonces no habitado quiere decir no colonizado, no productivo. Desierto es vida. Es diversidad. Es valentía caminante. Desierto es huella espectral del andar nómade. Desierto este todo ese espacio, ese modo de estar y de habitar el mundo por fuera de la lógica colonial; la lógica colonial en el sentido de ese espacio producido de una manera analítica, calculada, ordenada, desde el cálculo del interés. El desierto fluye, el desierto es movilidad, es espontaneidad, es sensibilidad, es apertura, huellas, la huella que va dejando la gente en las rutinas; no hay un cálculo, no hay un centro, no hay un origen, no hay una medida, ni propiedades ni género, ni rumbos definidos, sino que es la vida que fluye y la huella que va dejando la vida que fluye, y la gente que sigue esas huellas (Guión del documental Nómadas..., 2016). El desierto sólo está atravesado de huellas: senderos, pisadas de personas y animales, olores, restos muebles e inmuebles y el humo, que es un recurso de comunicación. El desierto está asediado por espectros, por huellas, por vestigios. La alteridad radical lo acecha como espectro: el otro está presente-ausente: los riales, las taperas con objetos, los restos óseos, restos cerámicos, vestigios de corrales y jagüeles, etc. Esta condición de "resto", de "huella" lo hace difícilmente asimilable a una representación unívoca, completa, a un cuerpo individualizado.

Así como con la espectrología, estas experiencias y registros nos acercan y nos identifican con las palabras derridianas y de Cacciari sobre los pueblos errantes y desérticos. El espacio del 
desierto carece de ordenamiento planificado. No hay calles individuales. La vía que recorre el desierto es la huella, no es un camino calculado; es la huella que ha dejado el caminante en su andar, vía errante es la raíz de la vida desértica. Merodear constituye el sostén, la raíz, el lugar en el mundo. Aquí se instala el rastro como forma de sociabilidad. Nosotros en la ciudad salimos a ver negocios, a visitar amigos y parientes, al cine; en el campo se sale a cortar el rastro, a ver qué y quién pasó, quién anduvo, pero a través de las huellas, a compartir a través de las huellas, a ver "si se pilla algo". La estructura del desierto es en su esencia nómade. Se anda, se campea, se merodea el desierto en un marco de conexión sensible con el universo a la espera de un acontecimiento imprevisible, lo que sea.

El desierto lavallino abraza, protege y amenaza a la vez. La arena, según los nativos, es como la madre, es metáfora de madre porque "la arena nos protege, nos protege del frío, del calor, de los vientos, uno mete la mano y hace una cuevita y es como el abrazo de la madre, el vientre de la madre. La tierra para nosotros no es cualquier cosa, es como la madre" (A.P, octubre 2016). Porque el campero "duerme donde lo pilla la noche", se hace un reparo en la ladera del médano, y la arena hace de cueva. La arena protege, a la vez que cabe la posibilidad de aparición de fuerzas maléficas, naturales (las víboras) y sobrenaturales (los espíritus).

El desierto lavallino es intolerante a la subordinación y a la jerarquía; carece de eje firme. Todos los espacios, las singularidades -los parajes, los bordos, los puestos, las ramadas- se hallan dispersas y cohabitadas; se pertenecen entre sí, porque ninguna dispone de un centro; no es un espacio jerárquicamente ordenado por un centro; es un pluriverso asediado por caminantes y camperos. Allí se da la reciprocidad hostis-hostes: el campero que anda necesitado de hospedaje, y que se convierte en huésped y el huesped que siempre se vuelve hostis, en condición de devenir caminante, necesitado de hospedaje, como el peregrino al que se refiere Derrida (1996). En el secano, cuando se anda campeando, 
siempre se encuentra hospedaje en los puestos; no hay forma de avisar y pactar de antemano una visita. Se aparece de improviso.

El desierto para Cacciari ${ }^{10}$, Deleuze y Guattari ${ }^{11}$ tiene una fisonomía, una microfísica específica: el desierto está hecho de materias diversas, móviles, fluctuantes, sin "forma orgánica", desorganizadas, que deshacen la figura y trazan sendas de indeterminación. Carece de centro, de origen, de rutas principales, de propiedades y de género, de rumbos definidos; solo está atravesado de sendas y huellas, que se borran y se desplazan con las trayectorias y contingencias de quienes transitan. Desierto no es lugar de la diferencia, sino que es el espacio de lo diverso, de la singularidad de lo múltiple, de los agenciamientos, del devenir imprevisible de la alteridad, irreductible a individualidad presente. Por ello "desierto" es un espacio político, es el espacio de lo político. El pueblo desértico es un pueblo acósmico, sin paisaje definido, no arable, indivisible, inedificable, como el archipiélago, dice Cacciari, el desierto es intolerante a la subordinación y a la jerarquía; carece de eje firme.

Con todo, mostramos aquí una noción de "desierto" en un sentido muy disímil al moderno de la "Conquista del desierto". Nos referimos con desierto no solo a una forma específica de espacialización, sino también a un modo de estar en el mundo: el nómade. El nomadismo es una forma de vivir, de sentir, pensar y estar en el mundo. Comprometidos con estos registros apostamos, en palabras de Deleuze y Guattari (1980), a una ciencia nómada, traducida a una etnografía nómada del desierto o espectrografía. La espectrografía es el pensamiento del desierto, el pensamiento nómade o nomadológica. Tal como lo han señalado los autores, hay maneras "lisas" o "estriadas" de estar en el espacio. Liso quiere decir abierto, circulante, marcado por trazos y huellas; estriado quiere decir cerrado, analítico, calculado, regu-

10 Tomamos como referencia Iconos de la ley (2009 [1985]) y El Archipiélago (1999 [1997]).

11 Tomamos como referencia Mille Plateaux (1980). 
lado. El trayecto nómada distribuye la vida en un espacio abierto, un espacio liso, sin calculo analítico que solo está marcado por "trazos", por huellas.

La nomadológica es un "modo de pensar", un "modo de estar" y un espacio de análisis. Reúne una estructura epistémica, una metafísica (cómo se piensa), saberes (positividades) y prácticas (lo que se hace), los cuales en conjunto se orientan a exponer los flujos múltiples y móviles de la materialidad. El nomadismo es una forma de vivir, de sentir, pensar y estar en el mundo. Es un pensamiento respecto de la vida, que la entiende en su sentido más abierto y político.

Una antropología del nomadismo, una antropología del desierto debe contemplar el valor de la huella, del rastro. Porque "desierto" es un modo de vida. Y en los desiertos lo que toma valor no son las piernas de los caminantes, sino las huellas y rastros que dejan los caminantes en el andar.

\section{Consideraciones finales}

Asumir un posicionamiento crítico implica conectar la revisión teórica con el examen de la propia experiencia etnográfica. Como etnógrafos nos corresponde realizar un permanente cuestionamiento e introspección crítica no solo sobre qué categorías estamos poniendo en circulación (a través de las cuales habilitamos, otorgamos autoridad científica a expresiones determinadas de la vida humana), sino también sobre qué forma de relacionarnos, de pensar y estar en común, construimos con las personas con las que trabajamos, lo cual será de crucial importancia en los resultados y tipos de saberes producidos. En las tres dimensiones señaladas -texto, proceso y experiencia-, la etnografía se revela no solo como cartografía de un grupo o colectividad, sino también de los itinerarios propios de la práctica científica respecto de axiomas teóricos, lógica institucional, lógica de articulación interinstitucional y lógicas de relación con el sujeto de estudio. 
Apostamos por una etnografía que pone como eje de construcción a la sensibilidad y la creatividad, ponderando su valor caminante y nómade. La etnografía pone en circulación léxicos y prácticas de lo común que identifican u oponen al etnógrafo con sus interlocutores en búsquedas compartidas, preocupaciones, sensibilidades, modos de vida, matrices ideológicas; e implica un andar diseñado por las trayectorias y contingencias de quienes transitan y comparten el recorrido etnográfico.

La etnografía se constituye, recrea, desarma y reconstituye contingentemente. Es decir, entre experiencias individuales y colectivas, la etnografía es un proceso. La escritura etnográfica nace también del desfasaje, del desajuste en el tiempo entre lo que se ve y se vivencia al inicio del contacto y lo que se ve y se vivencia al momento de la escritura, porque uno también es otro, otra persona. En este proceso se construyen relaciones, es decir, se construye un espacio comunitario, de una determinada manera. La etnografía define maneras de pensar y estar en-común.

En el marco de relaciones heterogéneas y escasamente exentas de conflictividad, la población nativa adscrita como Huarpe -nuestro caso etnográfico- se muestra cada vez más interesada y comprometida en examinar los múltiples empleos de la información relevada, lo cual se expresa en no otorgar información hasta que no se ponga en conocimiento y revisión colectiva el destino de la misma. Las relaciones que se construyen entre investigador/a, agentes religiosos, estatales e indígenas, e incluso turistas, son variadas y complejas, generándose múltiples situaciones etnográficas. Lejos de construirse relaciones orgánicas y equilibradas, se manifiestan como relaciones políticamente diversas. Con todo, las relaciones sociales que marcan las situaciones de campo son una construcción que implica un trabajo mutuo permanente. Lejos de ser inmediata, esta construcción tiene historicidad, y conjuga intereses, sistemas de representación, expectativas y afectos.

Las etnografías son parte elemental del dominio de saber sobre la diversidad de las formas con que pensamos, hacemos y cons- 
truimos el mundo. Y, según sea el posicionamiento desde el cual se construyan, pueden convertirse en dispositivos políticos ocluyentes o liberadores. Según sea la trayectoria y los modos en que se articulen los actores en el proceso etnográfico, realmente pueden volverse canales potentes de deconstrucción de "regímenes de verdad" instalados como universales, brindando marcos de interacción social que contribuyan tanto a superar las evidencias del sentido común, como a acceder y mostrar los modos diversos, y muchas veces ocultos, en los que la experiencia humana se organiza. Porque de eso se trata el proceso etnográfico, de vehicular de manera colectiva el potencial creativo que caracteriza el trabajo de campo.

\section{Referencias}

Asad, T. (1973). Introduction, en Anthropology \& the colonial Encounter. New York: Humanities Press.

Balandier, G. (1951). La situation coloniale: approche théorique. Cahiers Internationaux de Sociologie, XI, 44-79.

Bartolomé, M. (2007 [2002]). Librar el camino. Relatos sobre antropología y alteridad. Buenos Aires: Antropofagia.

Benedict, R. (1945). Patterns of Culture. New York: Mentor Books.

Benedict, R. (1934). Anthropology and the Abnormal. Journal of General Psychology, 10.

Boas, F. (1922 [1911]). The mind of primitive man. New York: The Macmillan Company.

Cacciari, M. (2009 [1985]). Iconos de la ley. Buenos Aires: La Cebra

Cacciari, M. (1999 [1997]). El Archipiélago. Figuras del otro en Occidente. Buenos Aires: Eudeba.

Clifford \& Marcus. (1986). Writting culture: the poetics and politics of the ethnography. Literature and art. Cambridge: Harvard University Press.

Deleuze, G. y Guattari, F. (1980). Mille plateaux (capitalisme y schizophénie). Paris: Minuit.

Derrida, J. (1996). Le monoliguisme de l'autre. Paris: Galilée. [Trad cast. El monolingüismo del otro]. Buenos Aires: Manantial. 
Derrida, J. (1996). Résistances de la psychanalize. París: Galilée.

Derrida, J. (1993). Spectres de Marx. L'État de la dette, le travail du deuil et la nouvelle Internationale. París: Galilée.

Evans-Pritchard, E. (1990 [1962]). Ensayos de Antropología Social. Buenos Aires: Siglo XXI.

Evans-Pritchard, E. (1940). The Nuer: A Description of the Modes of Livelihood and Political Institutions of a Nilotic People. Oxford: Clarendon Press.

Fabian, J. (1991). Presence and Representation, in Time and the work of anthropology: The Key Concepts (pp. 236-45). Londres y Nova Iroque: Routlege.

Freud, S. (2012 [1913-14]). Totem y tabú y otras obras, Trad. de José L. Etcheverry. Obras completas. Tomo XIII. Buenos Aires: Amorrortu.

Gluckman, M. (1987[1958]). Analise de uma situacão social na Zululandia moderna, en Feldman-Bianco, Bela Antropologia das sociedades contemporáneas (pp. 227-344). San Pablo: Pesser \& Bertelli.

Guber, R. (2001). La etnografía. Método, campo, reflexividad. Buenos Aires: Norma.

Guber, R. (1991 [2004]). El salvaje metropolitano. Reconstrucción del conocimiento social en el trabajo de campo. Buenos Aires: Paidós.

Katzer, L. (2016) "Diferencia-como-colonia", gubernamentalidad/biopolítica y Vivir bien (en-común): derivaciones decoloniales del pensamiento de Derrida, Foucault y la crítica poscolonial. Tabula Rasa, 25, 317-362.

Katzer, L. (2015). Márgenes de la etnicidad. De fantasmas, espectros y nomadológica indígena. Aportes desde una etnografía 'filolítica'. Tabula Rasa, 22, 31-51.

Katzer, L. (2011). El trabajo de campo como proceso. La etnografía colaborativa como perspectiva analítica. Revista Latinoamericana de Metodología de la Investigación Social, 2. CIES-CONICET. Universidad Nacional de Córdoba.

Lander, E. (2000). Ciencias sociales: saberes coloniales y eurocéntricos, en E. Lander (Comp.), La colonialidad del saber: eurocentrismo y ciencias sociales. Perspectivas latinoamericanas (pp. 4-23). Buenos Aires: CLACSO. 
Lassiter, L. (2005). The Chicago Guide to Collaborative Ethnography. Chicago: The University of Chicago Press.

Levi-Strauss, C. (1962). La pensée Sauvage. París: Librairie Plon.

Linton, R. (1959 [1945]). Cultura y personalidad. Buenos Aires: FCE.

Malinowski, B. (1926). Myth in primitive psychology. London: Kegal Paul \& Co.

Malinowski, B. (1922). Argonauts of the Western Pacific. London: Geo.

Mauss, M. (1926). Manuel d'ethnographie. Recuperado de http://www. uqac.uquebec.ca/zone30/Classiques_des_sciences_sociales/index.html.

Mauss, M. (1922-23). Essai sur le don. Forme et raison de l'échange dans les societés archaïques. Recuperado de http://www.uqac.uquebec. ca/zone30/Classiques_des_sciences_sociales/index.html.

Marcus, G. (2008). El o los fines de la etnografía: del desorden de lo experimental al desorden barroco. Revista de Antropología Social, 17, 27-48.

Marcus, G. y Fisher, M. (1986 [2000]). La Antropología como crítica cultural. Un momento experimental en las ciencias humanas. Buenos Aires: Amorrortu.

Mead, M. (1935). Sex and temperament in three primitive societies. New York: Morrow.

Mead, M. (1926). Coming of age in Samoa. A Psychological Study of Primitive Youth for Western Civilization. New York: Morrow.

Mignolo, W. (2000). La colonialidad a lo largo y a lo ancho: el hemisferio occidental en el horizonte colonialde la modernidad, en E. Lander (Comp.), La colonialidad del saber: eurocentrismo y ciencias sociales. Perspectivas latinoamericanas (pp. 34-52). Buenos Aires: CLACSO.

Pacheco de Oliveira J. (2006). Entre la ética del diálogo intercultural y una nueva modalidad de colonialismo, en J. Pacheco de Oliveira, Hacia una Antropología del indigenismo (pp. 181200). Río de Janeiro: Contra Capa.

Quijano, A. (2002). El regreso al futuro y las cuestiones de conocimiento, en C. Wash, F. Schiwy y S. Castro-Gomez (Eds.), Indisciplinar las ciencias sociales. Geopoliticas del conocimiento y colonialidad del poder. Perspectivas desde lo andino (pp. 45-60). Quito: Abya-Yala-Universidad Andina Simón Bolívar. 
Rapapport, J. y Ramos Pacho A. (2005). Una historia colaborativa: retos para el diálogo indígena-académico. Historia Critica, 29, 3962.

Rapport, N. y Overing, J. (2000) Social and Cultural Anthropology: The Key Concepts. Londres y New York. Routledge.

Restrepo, E. (2016). Etnografía: alcances, técnicas y éticas. Popayán: Envión Editores.

Stocking, G (1991). Colonial situation y Maclay, Kubary, Malinowski: Archetypes from the dreamtimes of Antrophology, en Colonial situations. Essays on the contextualitation of ethnographic (pp 3-67). Knowledge Madison: The University of Wisconsin Press.

Tamagno, L. (2001). Los Tobas en la casa del hombre blanco. La Plata: Al Margen.

Thomas, N. (1991). Against ethnography. Cultural Anthropology, 6(3), 306-322.

Trouillot, M-R. (2003). Anthropology and the Savage Slot: the poetics and politics of otherness, in Global transformations. Anthropology and the Modern World. New York: Palgrave Macmillan.

Trouillot, M-R. (1995). Silencing the Past: Power and the Production of History. Boston: Beacon Press.

Wolf, E. (1982). Europe and the People Without History. California: University of California Press (ed. 2010).

Worsley, P. (1970 [1964]). The third world. Nature of human society series. Chicago: The University of Chicago Press $2^{a}$ edición. 